\title{
Micrometeorological and chamber methods for measurement of nitrous oxide fluxes between soils and the atmosphere: Overview and conclusions
}

\author{
K. A. Smith, ${ }^{1}$ H. Clayton, ${ }^{2}$ J. R. M. Arah, ${ }^{1}$ S. Christensen, ${ }^{3}$ P. Ambus, ${ }^{3}$ \\ D. Fowler, ${ }^{4}$ K. J. Hargreaves, ${ }^{4}$ U. Skiba, ${ }^{4}$ G. W. Harris, ${ }^{5}$ F. G. Wienhold, ${ }^{5}$ \\ L. Klemedtsson, ${ }^{6}$ and B. Galle 6
}

\begin{abstract}
Emissions of $\mathrm{N}_{2} \mathrm{O}$ from agricultural grassland fertilized with $185 \mathrm{~kg} \mathrm{~N}^{-1}$ have been measured using a range of chamber and micrometeorological methods at a common site in the lowlands of Scotland. Measurements were made over similar periods (30 to $60 \mathrm{~min}$ ) by all methods, but the areas over which the fluxes were measured ranged from $0.008 \mathrm{~m}^{2}$ for the smallest chambers to $10^{4}$ to $10^{5} \mathrm{~m}^{2}$ for the micrometeorological methods. The fluxes measured using chambers ranged from less than 10 to more than $1700 \mathrm{ng} \mathrm{N} \mathrm{N}_{2} \mathrm{O}-\mathrm{N} \mathrm{m}^{-2} \mathrm{~s}^{-1}$; they were a factor of 3 larger from a previously grazed area than from the remainder. Fluxes showed great spatial variability and also a general decline with time following a peak after fertilization.

Micrometeorological measurements were made by eddy correlation using fast-response tunable diode laser absorption spectroscopy (TDLAS) and by aerodynamic (flux gradient) methods using Fourier transform infrared spectroscopy (FTIR), gas chromatography (GC), and TDLAS. All of the flux gradient methods provided similar fluxes of $\mathrm{N}_{2} \mathrm{O}$ over the ungrazed section of the field, with averages over the measurement period in the range 52 to $55 \mathrm{ng} \mathrm{N}_{2} \mathrm{O}-\mathrm{N} \mathrm{m}^{-2} \mathrm{~s}^{-1}$. Eddy correlation measurements with the TDL averaged 85 and $43 \mathrm{ng} \mathrm{m}^{-2} \mathrm{~s}^{-1}$ on the two days when measurements were made. Mean fluxes from the chamber methods, using GC, FTIR, and long-path infrared spectroscopy to detect $\mathrm{N}_{2} \mathrm{O}$, were larger than those from the micrometeorology and ranged from $280 \mathrm{ng} \mathrm{N} 2 \mathrm{O}-\mathrm{N} \mathrm{m}^{-2} \mathrm{~s}^{-1}$ for the smallest chambers to $210 \mathrm{ng} \mathrm{N} \mathrm{N}_{2} \mathrm{O}-\mathrm{N} \mathrm{m}^{-2} \mathrm{~s}^{-1}$ for the $0.13 / 0.49 \mathrm{~m}^{2}$ chambers and $300 \mathrm{ng} \mathrm{N} \mathrm{O}_{2} \mathrm{O} \mathrm{N} \mathrm{m}^{-2} \mathrm{~s}^{-1}$ for the $62 \mathrm{~m}^{2}$ chamber. The different techniques employed averaged over different spatial scales, and the measurements related to different areas of the field.

Nonetheless, the different micrometeorological methods gave similar fluxes. The higher values obtained by the chamber methods may have been due either to the spatial variability of the fluxes at the site, with the chambers being located in regions of relatively greater source strength, or to factors associated with the methods themselves.
\end{abstract}

\section{Introduction}

Soils have been identified by the Intergovernmental Panel on Climate Change (IPCC) as the major source of atmospheric nitrous oxide, $\mathrm{N}_{2} \mathrm{O}$. Of the total emissions estimated at $10-17.5 \mathrm{Tg} \mathrm{N}_{2} \mathrm{O}-\mathrm{N}^{-1}, 2.5-5.7 \mathrm{Tg}$ are attributed to tropical soils, but the estimates for temperate forest soils

\footnotetext{
${ }^{1}$ Scottish Agricultural College, School of Agriculture, Edinburgh, Scotland.

${ }^{2}$ University of Edinburgh, School of Agriculture, Edinburgh, Scotland.

${ }^{3}$ Institute of Population Biology, Copenhagen University, Copenhagen, Denmark.

${ }^{4}$ Institute of Terrestrial Ecology, Bush Estate, Midlothian, Scotland.

${ }^{5}$ Air Chemistry Department, Max Planck Institute for Chemistry, Mainz, Germany.

${ }^{6}$ Swedish Environmental Research Institute (IVL), Gothenburg, Sweden.

Copyright 1994 by the American Geophysical Union.

Paper number 94JD00619.

0148-0227/94/94JD-00619\$05.00
}

(0.05-2.0 Tg) and cultivated soils (0.03-3.0 Tg) are much more uncertain, and none at all is given for grasslands [Houghton et al., 1992].

In spite of these uncertainties, there is evidence that the flux of $\mathrm{N}_{2} \mathrm{O}$ from agricultural land (arable and fertilized grassland) is one of the major and growing contributors to total global emissions of this gas. Emissions increase with cultivation and disturbance and with increasing inputs of $\mathrm{N}$ in the form of mineral fertilizers and organic manures, especially to grassland [Ryden, 1981; Bouwman, 1990; Eichner, 1990]. Very little of the $\sim 80 \mathrm{Tg} \mathrm{N} \mathrm{y}^{-1}$ added as fertilizer worldwide remains in the soil-plant system. Most of it is ultimately denitrified, and only a small proportion has to be released as $\mathrm{N}_{2} \mathrm{O}$ rather than $\mathrm{N}_{2}$ to have a substantial effect on the global $\mathrm{N}_{2} \mathrm{O}$ budget [Robertson, 1993].

Improved assessment of $\mathrm{N}_{2} \mathrm{O}$ fluxes from fertilized land is a clear priority for research [International Global Atmospheric Chemistry (IGAC) Project, 1992; Melillo et al., 1992; Smith et al., 1994]. However, this is made difficult by the marked spatial and temporal variability of $\mathrm{N}_{2} \mathrm{O}$ emissions [e.g., Folorunso and Rolston, 1984; Christensen et al., 


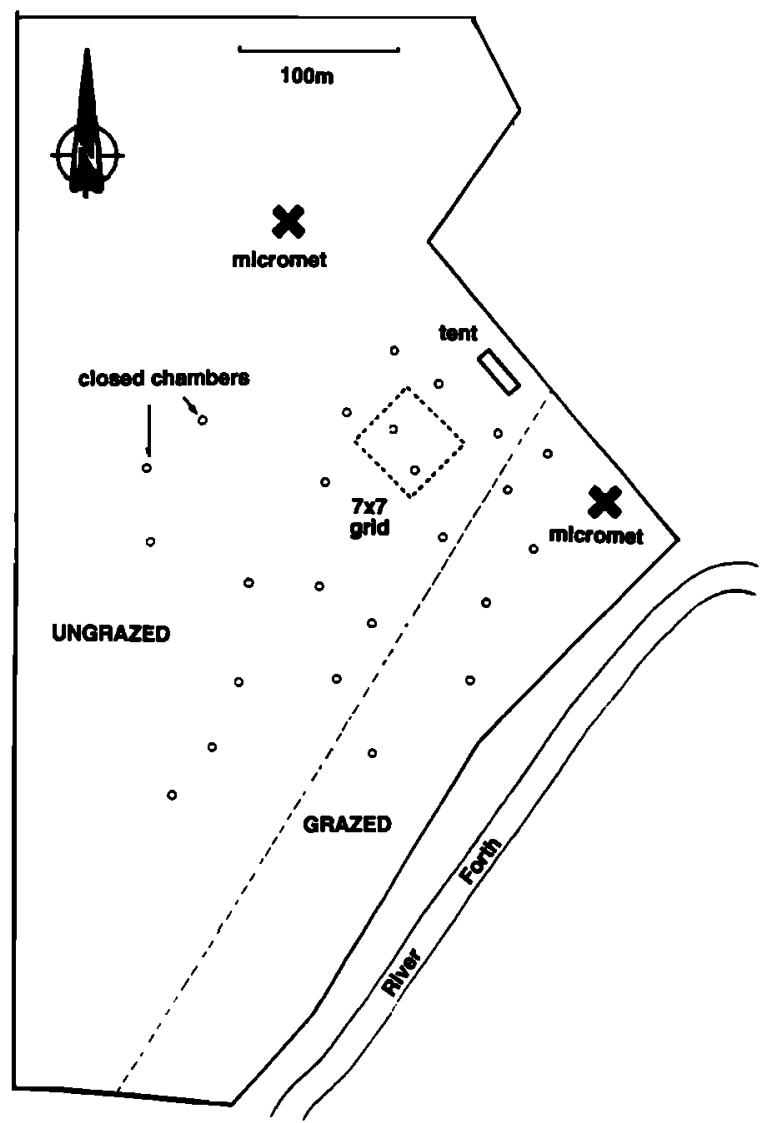

Figure 1. Site plan, Stirling experiment, April 1992.

1990a, b], which must be addressed when estimating fluxes on a regional or global scale. Better methods are required to estimate fluxes from larger areas and over longer time periods than has been generally possible up to now.

An experiment was carried out near Stirling, central Scotland, in April 1992 to measure $\mathrm{N}_{2} \mathrm{O}$ fluxes at different scales, ranging from $<1 \mathrm{~m}^{2}$ by traditional chamber methods with gas chromatographic analysis, to the field scale using micrometeorological methods [Ambus and Christensen, this issue; Arah et al., this issue; Clayton et al., this issue; Galle et al., this issue; Hargreaves et al., this issue; Smith et al., this issue; Wienhold et al., this issue]. In this paper we compare the various flux estimates, explore possible reasons for differences, where they occurred, and evaluate the potential of all the methods for satisfying the needs of international flux measurement programs.

\section{Site and Methods}

\section{Site and Environmental Conditions}

The experimental site was a flat grass field with a poorly drained clay soil near Stirling, central Scotland, fertilized with ammonium nitrate shortly before the experiment began. More details can be found in the work of Clayton et al. [this issue].

The location of the various flux measurement systems and the demarcation between that area of the field which had been grazed the previous year and the remainder are shown in Figure 1. The micrometeorological equipment was moved from the grazed to the ungrazed area on April 8.

During the measurement periods for micrometeorological fluxes (see below) between April 8 and April 12 the weather provided a westerly airflow over the site and a uniform fetch in the range 200 to $500 \mathrm{~m}$ from the instrument masts. Wind speeds during measurement periods ranged from 2 to $7 \mathrm{~m} \mathrm{~s}^{-1}$ at 3-m height. Air temperatures were in the range $5^{\circ}$ to $9^{\circ} \mathrm{C}$, with overcast skies and high relative humidities typical of cool wet spring weather in this region.

The methods used for measurement of $\mathrm{N}_{2} \mathrm{O}$ fluxes at the site are summarized in Table 1; full details of these methods are given in the individual papers. The following is a brief outline.

\section{Micrometeorological Methods}

A tunable diode laser (TDL) absorption spectroscopy system was used in both the flux gradient and the eddy correlation mode [Fowler and Duyzer, 1989]. The TDL

Table 1. Methods Used for Measurement of $\mathrm{N}_{2} \mathrm{O}$ Fluxes, Stirling, Scotland, April 1992

\begin{tabular}{|c|c|c|c|}
\hline Method & Instrumentation/Equipment & $\begin{array}{l}\text { Lowest Flux } \\
\text { Detectable, } \\
\text { ng } \mathrm{N}_{2} \mathrm{O}-\mathrm{N} \\
\mathrm{m}^{-2} \mathrm{~s}^{-1}\end{array}$ & Reference* \\
\hline \multicolumn{4}{|l|}{ Micrometerorological } \\
\hline $\begin{array}{l}\text { flux gradient and eddy } \\
\text { correlation }\end{array}$ & & $10-25 \dagger$ & Hargreaves et al. \\
\hline \multirow[t]{3}{*}{ flux gradient } & tunable diode laser (TDL) & $\sim 15 \dagger$ & Wienhold et al. \\
\hline & Fourier transform infrared (FTIR) & $\sim 15 \dagger$ & Galle et al. \\
\hline & $\begin{array}{l}\text { ECD gas chromatography (multiple } \\
\text { replicate analyses) }\end{array}$ & $10-25 \dagger$ & Arah et al. \\
\hline \multirow{6}{*}{$\begin{array}{l}\text { eddy correlation } \\
\text { Chamber based }\end{array}$} & TDL & $\sim 10 \dagger$ & Wienhold et al. \\
\hline & $\begin{array}{l}64 \mathrm{~m}^{2} \text { megachamber/FTIR (long-path } \\
\text { mode) }\end{array}$ & $2-3$ & Galle et al. \\
\hline & $64 \mathrm{~m}^{2}$ megachamber/Hawk long-path IR & ca. 30 & Smith et al. \\
\hline & $1 \mathrm{~m}^{2}$ chamber/FTIR & $<1$ & Galle et al. \\
\hline & $\begin{array}{l}0.49 \text { and } 0.13 \mathrm{~m}^{2} \text { closed chambers/ECD } \\
\text { gas chromatography }\end{array}$ & 2 & Clayton et al. \\
\hline & $\begin{array}{l}10 \text {-cm diameter }\left(0.008 \mathrm{~m}^{2}\right) \text { closed } \\
\text { chambers/ECD gas chromatography }\end{array}$ & 2 & Ambus and Christensen \\
\hline
\end{tabular}

*All this issue.

$\dagger$ Assuming a wind speed of $3 \mathrm{~m} \mathrm{~s}^{-1}$. 
Table 2. Comparison of Flux Measurements by Flux Gradient Micrometeorological, Combined Megachamber/LongPath IR, and Small Chamber Gas Chromatograph (GC) Methods

\begin{tabular}{|c|c|c|c|c|c|c|}
\hline \multirow[b]{2}{*}{ Method } & \multicolumn{6}{|c|}{$\mathrm{N}_{2} \mathrm{O}$ Flux, $\mathrm{ng} \mathrm{N} \mathrm{m} \mathrm{m}^{-1} \mathrm{~s}^{-1}$} \\
\hline & April 8 & April 9 & April 10 & April 11 & April 12 & April 13 \\
\hline Eddy correlation & ND & $75-113$ & ND & ND & ND & $38-48$ \\
\hline \multicolumn{7}{|l|}{$\begin{array}{l}\text { Flux gradient } \\
\text { micrometeorological }\end{array}$} \\
\hline TDL & ND & ND & $20-70^{*}$ & $51-59$ & ND & ND \\
\hline FTIR & $47-103$ & $0-127$ & $34-55$ & ND & ND & ND \\
\hline GC & 45 & 35 & ND & 65 & $73-105$ & ND \\
\hline Megachamber/long-path IR & ND & ND & $247(222-321) \dagger$ & $295(266-384) \dagger$ & ND & ND \\
\hline $\begin{array}{l}0.126 \mathrm{~m}^{2} \text { chambers within } \\
\text { tent area/GC analysis }\end{array}$ & ND & ND & $61-230(128) \ddagger$ & ND & ND & ND \\
\hline $\begin{array}{l}0.126 \text { and } 0.49 \mathrm{~m}^{2} \\
\text { chambers } \$ / \mathrm{GC} \text { analysis }\end{array}$ & 149-824(355) 末 & $13-414(160) \ddagger$ & $29-337(177) \ddagger$ & $24-488(205) \ddagger$ & $21-406(142) \ddagger$ & $22-528(218) \ddagger$ \\
\hline $\begin{array}{l}0.0079 \mathrm{~m}^{2} \text { chambers in } \\
49 \times 49 \mathrm{~m} \text { grid } / \mathrm{GC} \text { analysis }\end{array}$ & $(191) \ddagger$ & $74-854(292) \ddagger$ & ND & ND & ND & ND \\
\hline
\end{tabular}

ND, not determined.

*44-64 during the afternoon and 20-70 under inversion conditions.

$\uparrow$ Single integrated value and uncertainty range from -10 to $+30 \%$ of value.

$\ddagger$ Range and mean (mean calculated according to the uniformly minimum variance unbiased estimator method [Finney, 1941].

§Ungrazed area only.

[Wienhold et al., this issue] was a laboratory-built system using a multipass White cell with an optical path of $45.9 \mathrm{~m}$, operated at reduced pressure, and scanning the single $\mathrm{N}_{2} \mathrm{O}$ line at $4.472 \mu \mathrm{m}$. The time response of the system, including the inlet and drying sections, was $200 \mathrm{~ms}$. Two sonic anemometers (Dobbie and Gill) were used for eddy correlation measurements at heights of $2.25 \mathrm{~m}$ and $2.75 \mathrm{~m}$, respectively.

A Fourier transform infrared (FTIR) long-path absorption spectrometer (Bomem, Toronto, Canada) was used with a 25-L White cell (pathlength $139 \mathrm{~m}$ ), to measure fluxes with a small chamber and by the flux gradient method.

Flux gradient measurements were also made by repeated gas chromatographic analysis of air samples collected in bags from different heights over 30-min periods [Arah et al., this issue], in conjunction with micrometeorological measurements [Hargreaves et al., this issue].

\section{Chamber Methods}

The FTIR was also used in an open White cell arrangement with a spacing between mirrors of $25 \mathrm{~m}$ and an optical pathlength of $1 \mathrm{~km}$, within a large tent, or "megachamber" [Galle et al., this issue]. A Hawk long-path IR gas monitor (Siemens Plessey Controls Limited, Poole, Dorset, England) was also used in the megachamber; a single retroreflector at a spacing of $25 \mathrm{~m}$ gave an absorption path of $50 \mathrm{~m}$ [Smith et al., this issue].

Twenty-four conventional closed chambers, 0.13 and 0.49 $\mathrm{m}^{2}$ in area, were used in conjunction with ECD gas chromatography to measure fluxes from both the grazed and the ungrazed parts of the site [Clayton et al., this issue]. In addition, very small $\left(10-\mathrm{cm}\right.$ diameter, $\left.0.008 \mathrm{~m}^{2}\right)$ chambers were located in a series of spatial arrays to study the spatial variability of the $\mathrm{N}_{2} \mathrm{O}$ flux. Here too, $\mathrm{N}_{2} \mathrm{O}$ was measured by ECD gas chromatography [Ambus and Christensen, this issue].

Measurements of $\mathrm{N}_{2} \mathrm{O}$ fluxes averaged over an hour were provided by chamber techniques daily throughout the period
April 8-13. The micrometeorological methods provided 30min average fluxes over much shorter periods throughout the measurement campaign. The eddy correlation fluxes were restricted to April 9 and 13, while flux gradient measurements were available for parts of April 8-12 (Table 2).

Attempts were made to coordinate measurements using the different systems as far as possible. However, because of instrumental and logistic problems, constraints on analysis time, and occasionally unsuitable weather conditions, measurements were not always made simultaneously, and this should be borne in mind when comparing the results, especially in view of the diurnal variation in flux observed by Clayton et al. [this issue] and Galle et al. [this issue].

\section{Resolution and Detection Limits}

The analytical techniques employed for flux gradient measurements could resolve very small differences in $\mathrm{N}_{2} \mathrm{O}$ concentration. The GC-based method was able to resolve $\mathrm{N}_{2} \mathrm{O}$ concentration differences of -2 parts per billion by volume (ppbv), when $>10$ replicate injections were made. The TDL had an absolute resolution of $1 \mathrm{ppbv}$ for an integration period of $1 \mathrm{~min}$; when averaged over 10 and 30 min, the resolution became 0.5 and 0.25 ppbv, respectively. The FTIR could resolve differences of $0.5 \mathrm{ppbv}$, when the ratios of the spectra for the two sampling heights were determined over a 12-min period. Temperature-induced instrumental drift limited the resolution of the TDL and GC analysis systems [Arah et al., this issue; Wienhold et al., this issue].

In eddy correlation mode the performance of the TDL provided a flux detection limit of the order of $10 \mathrm{ng} \mathrm{N} \mathrm{N}_{2} \mathrm{O}-\mathrm{N}$ $\mathrm{m}^{-2} \mathrm{~s}^{-1}$. The chamber/GC methods detected fluxes at this site as low as $7 \mathrm{ng} \mathrm{N}_{2} \mathrm{O}-\mathrm{N} \mathrm{m}^{-2} \mathrm{~s}^{-1}$ and would have been capable of resolving fluxes as low as $2 \mathrm{ng} \mathrm{m}^{-2} \mathrm{~s}^{-1}$. The detection limit of fluxes measured using the Hawk in the megachamber was about $30 \mathrm{ng} \mathrm{N}_{2} \mathrm{O}-\mathrm{N} \mathrm{m}^{-2} \mathrm{~s}^{-1}$, while the corresponding value for the FTIR in the same mode was at least an order of magnitude better (Table 1). 


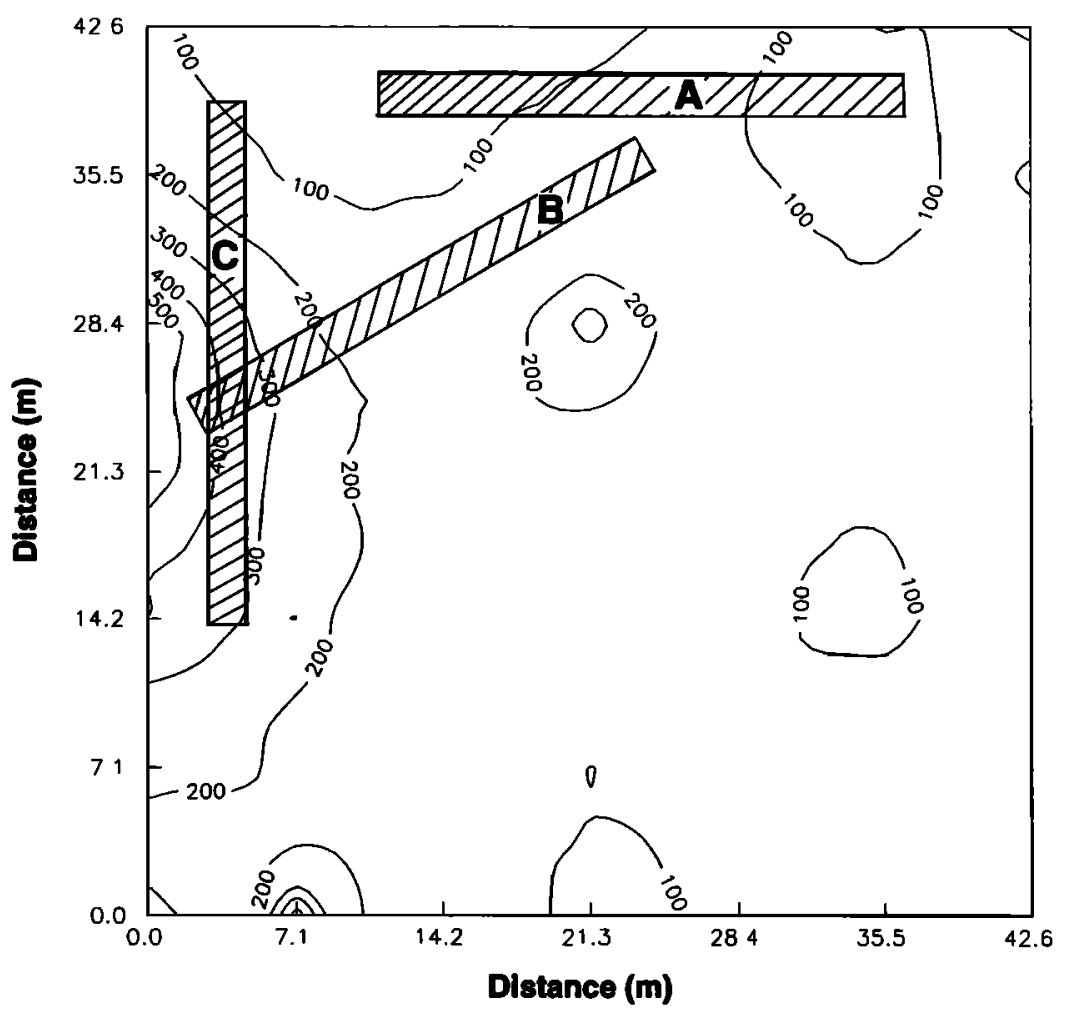

Figure 2a. "Contour map" of $\mathrm{N}_{2} \mathrm{O}$ flux within $42.6 \mathrm{~m} \times 42.6 \mathrm{~m}$ grid sampling area, showing three simulated positions of megachamber (values on contour lines in $\mathrm{g} \mathrm{N}_{2} \mathrm{O}-\mathrm{N} \mathrm{ha}^{-1} \mathrm{~d}^{-1}$ ).

\section{Results and Discussion}

\section{Comparison of Flux Measurements: Effects of Spatial and Temporal Variability}

Nitrous oxide fluxes arising from denitrification, which occurs in anaerobic microsites within a predominantly aerobic medium [Sexstone et al., 1985; Christensen et al., 1990a], tend to be more spatially variable than those arising from the aerobic process of nitrification. Incubations of soil cores with and without acetylene [Clayton et al., this issue] suggested that the major $\mathrm{N}_{2} \mathrm{O}$ source at the Stirling field site was denitrification. This conclusion was supported by measurements of NO emissions, using a chemiluminescence analyzer (TECO 43s) and techniques described in detail by Skiba et al. [1992], between April 10 and 13. All fluxes of NO were small (1.4-2 ng NO-N m $\mathrm{m}^{-2} \mathrm{~s}^{-1}$ ), suggesting that nitrification did not make a significant contribution to the emissions.

Measurements with chambers [Ambus and Christensen, this issue; Clayton et al., this issue] revealed a fairly persistent pattern of $\mathrm{N}_{2} \mathrm{O}$ production: "hot spots" tended to remain "hot" throughout. Spatial heterogeneity as measured by the 0.49 and $0.13 \mathrm{~m}^{2}$ chambers at separations $>50$ $\mathrm{m}$ [Clayton et al., this issue] appeared to be pure nugget variability [Oliver and Webster, 1991]. These results suggest that to characterize fluxes at the field scale by this method, using a strategy involving systematic relocation of chambers might be sensible, especially where chamber numbers are small.

Data from the small $\left(0.008 \mathrm{~m}^{2}\right)$ chambers [Ambus and Christensen, this issue] were analyzed to determine the hypothetical flux values that would have been obtained using a megachamber [Galle et al., this issue; Smith et al., this issue] to enclose $62 \mathrm{~m}^{2}$ areas in the three positions shown in Figure $2 \mathrm{a}$. These calculations indicate that a movement of a few tens of meters could still give a fivefold range of flux values: positions $A, B$, and $C$ have calculated fluxes of 84 , 253, and $421 \mathrm{ng} \mathrm{N} \mathrm{m} \mathrm{s}^{-1}\left(73,219\right.$, and $\left.364 \mathrm{~g} \mathrm{~N} \mathrm{ha}^{-1} \mathrm{~d}^{-1}\right)$. This compares with about a 12-fold range actually observed for the small chambers used in the grid sampling, from 64 to $738 \mathrm{ng} \mathrm{N} \mathrm{N}_{2} \mathrm{O}-\mathrm{N} \mathrm{m}^{-2} \mathrm{~s}^{-1}$. A simulation of 51 random positions of the megachamber in the $43 \mathrm{~m} \times 43 \mathrm{~m}$ grid gave a mean of $145 \mathrm{ng} \mathrm{N} \mathrm{m}^{-2} \mathrm{~s}^{-1}\left(125 \mathrm{~g} \mathrm{~N} \mathrm{ha}^{-1} \mathrm{~d}^{-1}\right)$ and a coefficient of variation of $25 \%$, compared with a mean of 253 and a $\mathrm{CV}$ of $67 \%$ for the three positions in Figure 2a, and with a CV of $75 \%$ determined for the 240.13 and $0.49 \mathrm{~m}^{2}$ chambers. It is worth noting that even with 51 samplings the simulated fluxes still showed a skewed distribution (Figure $2 b$ ).

Table 2 summarizes the $\mathrm{N}_{2} \mathrm{O}$ fluxes measured by the various methods over the six consecutive days, April 8-13, during which the micrometeorological fetch lay predominantly over the ungrazed area of the field (Figure 1). Figure 3 shows the fluxes determined by the gradient and eddy correlation methods and the 0.13 and $0.49 \mathrm{~m}^{2}$ chambers on the ungrazed area over the same period.

The three flux gradient micrometeorological methods can be compared over the period April 8-11. The emission fluxes obtained by the three systems averaged over half-hour periods ranged from 20 to $150 \mathrm{ng} \mathrm{N}_{2} \mathrm{O}-\mathrm{N} \mathrm{m}^{-2} \mathrm{~s}^{-1}$. The different measuring systems averaged over slightly different sections of the field because the sample inlets were on different masts for the different detectors. However, in the short periods when the fetch for the measurement systems was restricted to the ungrazed section of the field, the average fluxes were very similar: $54 \pm 35(n=6), 55 \pm 33$ 
$(n=42)$, and $52 \pm 8(n=6) n g \mathrm{~N}_{2} \mathrm{O}-\mathrm{N} \mathrm{m}^{-2} \mathrm{~s}^{-1}$, for the GC, FTIR, and TDL systems, respectively.

The measurement by the GC micrometeorological method showed a much larger flux (170 ng $\mathrm{N}_{2} \mathrm{O}-\mathrm{N} \mathrm{m}^{-2} \mathrm{~s}^{-1}$ ) when the equipment was situated in the grazed section of the field on April 4; chamber measurements in this area also showed larger fluxes on that day: $18-1620 \mathrm{ng} \mathrm{N}_{2} \mathrm{O}-\mathrm{N} \mathrm{m}^{-2} \mathrm{~s}^{-1}$, with a mean of 603 .

Detecting a flux with the gradient technique depends on the concentration difference between the highest and lowest sampling points exceeding the resolution of the analysis system employed. The taller the sampling mast, the greater this concentration difference is likely to be. In practice the height is limited by the requirement of fetch uniformity; $1 \mathrm{~m}$ of mast corresponds to $\sim 200 \mathrm{~m}$ of fetch. The concentration gradient corresponding to any given flux varies with wind speed; the higher the speed, the smaller the gradient. Moreover, when wind speeds are below the stalling speed of the anemometers, the concentration gradient may be large, but its interpretation is impossible [Hargreaves et al., this issue].

Comparing the chamber and micrometeorological methods is not a straightforward matter. First, the "footprint" of the measurements by micrometeorological methods is not a simple linear function of the upwind fetch. The problem has been analyzed by Leclerc and Thurtell [1990], using a numerical solution of the diffusion equation to calculate the probability density of the areal contributions to the measured vertical flux at a micrometeorological mast. This approach requires the source strength of $\mathrm{N}_{2} \mathrm{O}$ to be spatially uniform at a scale of 10 to $20 \mathrm{~m}$ to avoid the development of significant advection errors due to horizontal gradients in $\mathrm{N}_{2} \mathrm{O}$ concentrations. The field measurements using chambers (both small and large) show the widely reported spatial variability in $\mathrm{N}_{2} \mathrm{O}$ emission between adjacent chambers. However, the patch of large emission with an approximate dimension of $20 \mathrm{~m}$ (Figure 2a) introduces further complexity into the process of estimating the footprint of the field for the micrometeorological techniques. The variability in the log linear, height $\mathrm{v} \mathrm{N}_{2} \mathrm{O}$ measurements [Hargreaves et al., this issue] may be regarded as evidence of the conditions at the

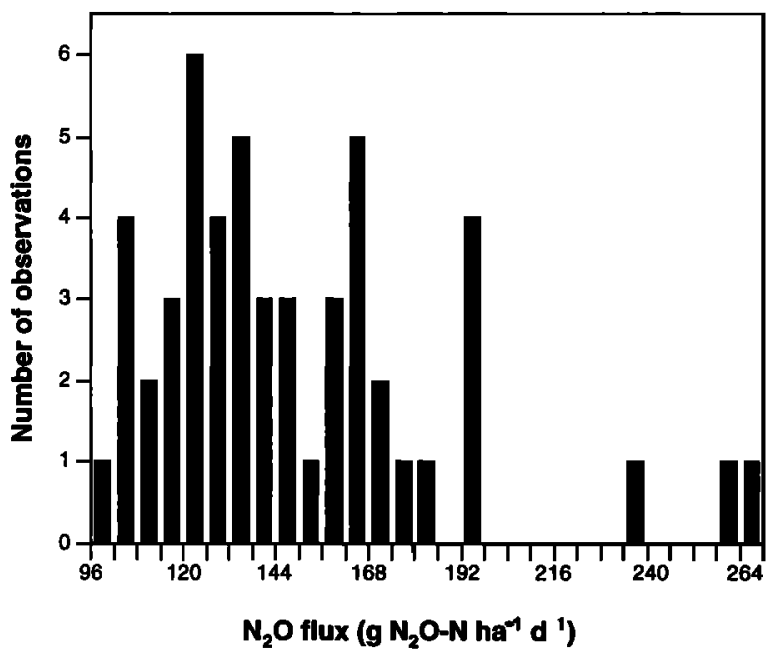

Figure 2b. Frequency distribution of fluxes from 51 simulated random positions of megachamber.

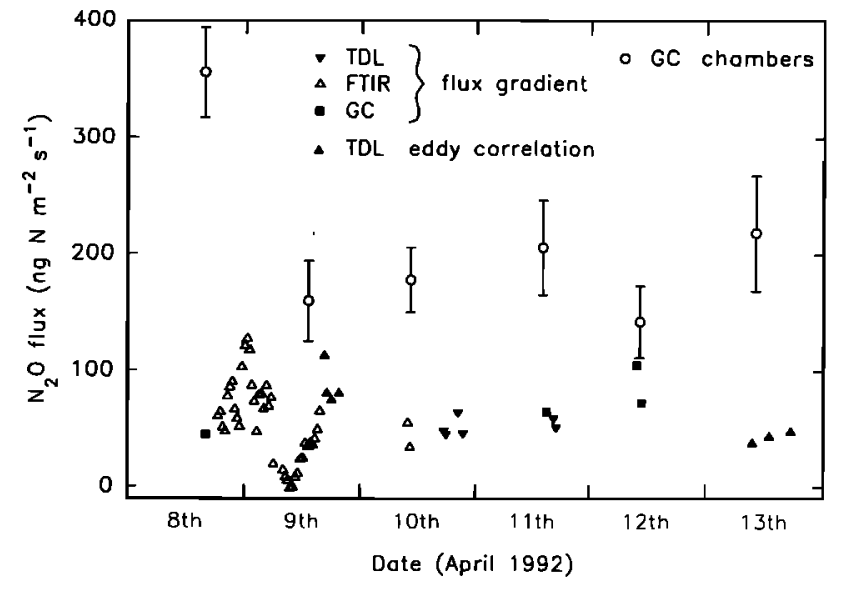

Figure 3. $\mathrm{N}_{2} \mathrm{O}$ fluxes measured by micrometeorological and chamber methods.

site being less than ideal for these techniques and may well be a consequence of the spatial heterogeneity of emission fluxes. In spite of these difficulties it is helpful to quantify the likely footprint of the field for the flux measurements reported, adopting similar assumptions to those of Leclerc and Thurtell [1990] for a site which has similar aerodynamic properties and making the additional and very important assumption that there were no horizontal gradients in the $\mathrm{N}_{2} \mathrm{O}$ flux. It is estimated that the upwind $60 \mathrm{~m}$ of fetch contributed approximately $50 \%$ of the measured flux which had a maximum in its probability distribution at about $30 \mathrm{~m}$.

The objective of the entire study was to obtain measurements of $\mathrm{N}_{2} \mathrm{O}$ emission fluxes using techniques which integrate the flux over different spatial scales. While this objective has clearly been achieved, it is important to recognize the extent to which differences between the averaging areas prevent a strict comparison of fluxes. The comparisons between methods and the reported fluxes are therefore used to identify weaknesses in the techniques and show the mechanisms by which the differences arise rather than to obtain the "correct" flux for a particular averaging area.

The sites of chamber measurements in the ungrazed section of the field are shown in Figure 1. The nearest chamber measurements to the micrometeorological mast were at a distance of about $100 \mathrm{~m}$. The measured fluxes from the chambers over this section of the field generally showed values in the range $50-200 \mathrm{ng} \mathrm{N}_{2} \mathrm{O}-\mathrm{N} \mathrm{m}^{-2} \mathrm{~s}^{-1}$. The range was therefore similar to that of the micrometeorological measurements. However, the mean fluxes by the chamber methods were about a factor of 2 larger. There are several possible causes for this apparent discrepancy. First, the conditions within the chambers may have been modified so as to enhance the rates of $\mathrm{N}_{2} \mathrm{O}$ emission. This is quite possible if, for example, the temperatures of the surface 1 to $3 \mathrm{~cm}$ of the soil were increased by even a small amount. This could be expected to result in an increase in the anaerobic volume in which denitrification (believed to be the main source of the $\mathrm{N}_{2} \mathrm{O}$; see below) would take place, as well as an increase in the rate per unit anaerobic volume [Smith, 1977]. Alternatively, fluxes may have been influenced in some way by plant physiological processes, which would have been significantly modified by the chamber conditions. A factor working in the opposite direction (i.e., underesti- 
mation of the fluxes) is the possible reduction in the diffusion gradient into closed chambers due to $\mathrm{N}_{2} \mathrm{O}$ accumulation. However, this was found not to occur in this experiment [Clayton et al., this issue].

The micrometeorological flux measurements over the fetch defined above may also have differed from the actual surface flux as a consequence of advection errors produced by horizontal gradients in concentration [Fowler and Duyzer, 1989]. The magnitude of the error in the flux is governed by the windspeed, height of sampling, and the horizontal concentration gradient. If the chamber measurements are taken to be representative of the field outside the nearest 50-m radius from the masts and the flux in the "inner zone" was a factor of 2 smaller, then the flux divergence in the micrometeorological measurements would have been of the same order as the measured flux (i.e., typically $100 \mathrm{ng}$ $\mathrm{N}_{2} \mathrm{O}-\mathrm{N} \mathrm{m}^{-2} \mathrm{~s}^{-1}$ ).

Evidence of spatial heterogeneity in the source strength may also be obtained from the vertical gradients in $\mathrm{N}_{2} \mathrm{O}$ concentrations. There were occasions when the lowest four points of the gradient provided good log linear profiles, while the highest point differed significantly from that expected (i.e., outside the $95 \%$ confidence interval). In these cases the fluxes were calculated from the four point profiles, but the additional point provides evidence that the $\mathrm{N}_{2} \mathrm{O}$ source strength changed at some point in the upwind fetch. In the absence of much greater vertical resolution of the gradients, any more detailed interpretation of these data would be speculative. The corollary of this argument is that two-point sampling of vertical gradients for flux measurements of gases which show large spatial variability in emission is likely to introduce substantial errors that cannot be quantified from the data.

Gas-chromatography-based flux gradient measurements could be performed no more than twice a day because of the long analysis times. Had samples been taken at only two heights rather than five, five fluxes could have been measured per day, but potentially valuable information about the shape of the concentration gradient would have been lost. Both the TDL and the FTIR were capable of virtually continuous monitoring of concentration gradients and online data analysis. The TDL was not operated in eddy correlation mode for periods longer than half an hour during this experiment, and data were analyzed off line [Wienhold et al., this issue]. Chamber measurements made daily during the mornings showed a decrease between April 8 and 9, followed by relatively constant emissions over the next four days [Clayton et al., this issue].

\section{Research Priorities and Method Selection}

The acquisition of representative $\mathrm{N}_{2} \mathrm{O}$ flux data for agricultural ecosystems, not merely over whole annual cycles but also over the lifetime of characteristic cropping rotations, is a major priority for future research, if we are to resolve the uncertainties in the global $\mathrm{N}_{2} \mathrm{O}$ budget [Houghton et al., 1992].

To meet this priority, work will have to be carried out both in those regions, such as North America, Western Europe, and Australasia, where there is already much experience of the difficulties involved, and, perhaps more significantly, in those regions where little or no research of this type has been done hitherto.

Where land use practices involve small fields with differ- ent crops and fertilizer rates, plots with different treatments, wind breaks, and so on, micrometeorological methods are difficult to apply. In such situations, chamber methods, both those using conventional small $\left(<1 \mathrm{~m}^{2}\right)$ chambers and those based on the megachamber, have advantages.

Several systems involving automation of small chamber operation, gas sampling, and GC analysis have been, or are being developed [e.g., Christensen, 1983; Loftfield et al., 1992; International Atomic Energy Agency (IAEA), 1992; Smith et al., 1994], variously deployed in the measurement of trace gas fluxes in a temperate forest, temperate agricultural cropping systems, and rice paddies, and their use is likely to increase. They reduce the labor requirement for field sampling and analysis enormously and make much more feasible both long-term measurements and intensive short-term investigations required for process-related studies. Also, they make possible measurements at remote sites over longer periods, or more frequently, than is possible by means of field campaigns or regular sampling expeditions.

The megachamber [Galle et al., this issue; Smith et al., this issue] merits further development to (1) improve the gas impermeability, to reduce the need for corrections to fluxes for losses, (2) make movement between locations at the same site less time consuming, to allow fluxes to be measured from more experimental plots or replicate areas. An alternative to increased portability is replication of the large chamber itself. Here, the use of cheap plastic sheet and cheap and simple frameworks has obvious cost advantages over purpose-built tentlike systems.

Concentration changes in the megachamber may be measured in real time by either of the two long-path IR instruments (FTIR/Hawk) or later (in the laboratory) by GC analysis. The FTIR is about $\mathbf{1 0}$ times more sensitive than the Hawk, but the Hawk is easier to set up and maintain, which may be an important consideration. Conversely, correction for leaks is more straightforward with the FTIR, which can analyze two gases at once. GC analysis has about the same detection limit as the Hawk. Moreover, a single GC system could be used to make simultaneous measurements from a large number of chambers.

The work by Wienhold et al. [this issue] shows that tuneable diode laser absorption spectroscopy (TDLAS) techniques now have sufficient sensitivity to permit the measurement of relatively low fluxes of $\mathrm{N}_{2} \mathrm{O}$ at the field scale by flux gradient and eddy correlation methods. The same is true for FTIR absorption spectroscopy [Galle et al., this issue] in the flux gradient mode. However, it is recognized that the development of the technique for general use will occur only in the medium term, both because of the complexity and the cost of the analytical system and the associated instrumentation necessary for micrometeorological flux determinations, and the time required for setting up, calibration, and data analysis. It is likely that in the immediate future the technique will find application mostly in short-term intensive studies.

A variant of the flux gradient method, using the TDL or the FTIR, which should be tried in the future is the analysis of bag samples "off line" by pumping them through a White cell. One of our groups (K. J. Hargreaves and D. Fowler, unpublished material, 1993) has already done this by TDL for methane in samples collected by aircraft, and it should also work for $\mathrm{N}_{2} \mathrm{O}$. The use of such combinations would extend the range of fluxes measurable down to far lower 
levels than those attained by the similar procedure using GC analysis. The combination of bag sample collection and instrumental analysis is also potentially applicable to the conditional sampling, or relaxed eddy accumulation, method [Businger and Oncley, 1990].

\section{Conclusions}

Measurements of $\mathrm{N}_{2} \mathrm{O}$ emission fluxes from an agricultural soil were obtained by eight different methods at a common site. The methods, which measured fluxes over very different areas $\left(0.008 \mathrm{~m}^{2}\right.$ to $\left.10^{5} \mathrm{~m}^{2}\right)$, were used to quantify the spatial variability in emission fluxes and to average emission from the field.

Fluxes from the ungrazed part of the field, measured using closed chambers $<1 \mathrm{~m}^{2}$ in area, varied from 7 to $820 \mathrm{ng}$ $\mathrm{N}_{2} \mathrm{O}-\mathrm{N} \mathrm{m}^{2} \mathrm{~s}^{-1}$ during the campaign, with a coefficient of variation around $75 \%$. Geostatistical analysis suggested that using larger $\left(62 \mathrm{~m}^{2}\right)$ chambers might reduce this variation by a factor of approximately 3 ; this factor is smaller than that expected from random microsite variability; it indicates larger-scale $(10-100 \mathrm{~m})$ heterogeneity at the Stirling site. Micrometeorological methods have been shown to integrate (average) small-scale spatial variability in flux, but they are subject to error if large systematic variations (e.g., differences of a factor of 2 or more over distances of $100 \mathrm{~m}$ or so) are present in the upwind fetch. The differences we observed between averaged micrometeorological and averaged chamber measurements may have arisen from fetch heterogeneity of this order; alternatively, temperature-induced changes in $\mathrm{N}_{2} \mathrm{O}$ emissions from the soil under the chambers may be implicated. A thorough investigation is required; the development of large chambers and the use of geostatistical methods to analyze results from smaller ones provide a means of bridging the gap between the micrometeorological and the chamber-based techniques. The measurements also revealed the strengths of the different methods, which are summarized as follows:

TDL spectroscopy [Wienhold et al., this issue] is the only analysis technique currently capable of providing the resolution and speed of response required for eddy correlation measurements of $\mathrm{N}_{2} \mathrm{O}$ flux (200 ms response time). It can also be used to measure atmospheric concentration gradients, as part of the flux gradient method, and if required, it could be adapted for use with open or closed flux chambers.

The FTIR [Galle et al., this issue] offers parts per billion by volume resolution over timescales of minutes, more than adequate for flux gradient measurements, and it can also be used to measure concentration changes in conventional or megachambers.

A gas-chromatography-based method for flux gradient work [Arah et al., this issue] is relatively cheap, though cumbersome. Where automated sample injection is required for other purposes (e.g., streamlining routine discrete analyses), it provides the option of occasional micrometeorological flux measurements at little additional cost.

Small chambers and the Hawk long-path IR instrument [Smith et al., this issue] used in conjunction with a megachamber can measure $\mathrm{N}_{2} \mathrm{O}$ fluxes from areas of $10^{1}-10^{2} \mathrm{~m}^{2}$ in circumstances where micrometeorological techniques are not applicable (e.g., small or uneven fields, experimental plots). TDL, FTIR, and GC techniques may also be employed with a large chamber (TDL and FTIR directly or via bag samples, GC via bag or discrete syringe samples).
The FTIR analysis technique is capable of measuring many gases simultaneously. It and the TDL and GC systems can also be applied to the recently developed conditional sampling (eddy accumulation) approach to trace gas flux measurement.

A geostatistical analysis of flux data from replicated chambers [Ambus and Christensen, this issue; Clayton et al., this issue] is required to quantify the scale of fetch homogeneity/ heterogeneity; without this information, megachamber and two-point gradient methods [Hargreaves et al., this issue] remain open to query. Measuring concentration gradients by sampling at four or more heights reduces this uncertainty and provides additional information on the homogeneity of the fetch. Chamber methods are also particularly valuable for investigating processes or responses to modifications of the soil/plant environment.

Acknowledgments. We thank the Commission of the European Communities for supporting this work as part of STEP project CT 90-0028. We also acknowledge the financial support provided by NERC through its TIGER (Terrestrial Initiative in Global Environmental Research) program, award GST/02/600 (UK); the Max Planck Society (Germany); and Vattenfall AB, the Swedish Environmental Research Institute, and the Nordic Ministerial Council (Sweden).

\section{References}

Ambus, $\mathrm{P}$., and S. Christensen, Measurement of $\mathrm{N}_{2} \mathrm{O}$ emission from a fertilized grassland: An analysis of spatial variability, $J$. Geophys. Res., this issue.

Arah, J. R. M., I. J. Crichton, K. A. Smith, H. Clayton, and U. Skiba, Automated gas chromatographic analysis system for micrometeorological measurements of trace gas fluxes, J. Geophys. Res., this issue.

Bouwman, A. F., Exchange of greenhouse gases between terrestrial ecosystems and the atmosphere, in Soils and the Greenhouse Effect, edited by A. F. Bouwman, pp. 61-127, John Wiley, New York, 1990.

Businger, J. A., and S. P. Oncley, Flux measurement with condjtional sampling, J. Atmos. Oceanic Technol., 7, 349-352, 1990.

Christensen, S., Nitrous oxide emission from the soil surface: Continuous measurement by gas chromatography, Soil Biol. Biochem., 15, 481-483, 1983.

Christensen, S., S. Simkins, and J. M. Tiedje, Spatial variation in denitrification: Dependency of activity centers on the soil environment, Soil Sci. Soc. Am. J., 54, 1608-1613, 1990a.

Christensen, S., S. Simkins, and J. M. Tiedje, Temporal patterns of soil denitrification: Their stability and causes, Soil Sci. Soc. Am. $J ., 54,1614-1618,1990 \mathrm{~b}$.

Clayton, H., J. R. M. Arah, and K. A. Smith, Measurement of nitrous oxide emissions from fertilized grassland using closed chambers, J. Geophys. Res., this issue.

Eichner, M. J., Nitrous oxide emissions from fertilized soils: Summary of available data, J. Environ. Qual., 19, 272-280, 1990.

Finney, D. J., On the distribution of a variate whose logarithm is normally distributed, $R$. Stat. Soc. London J. Suppl., 7, 155-161, 1941.

Folorunso, O. A., and D. E. Rolston, Spatial variability of fieldmeasured denitrification gas fluxes, Soil Sci. Soc. Am. J., 48, 1214-1219, 1984.

Fowler, D., and J. Duyzer, Meteorological techniques for the measurement of trace gas exchange, in Exchange of Trace Gases Between Terrestrial Ecosystems and the Atmosphere, edited by M. O. Andreae and D. S. Schimel, pp. 189-207, John Wiley, New York, 1989.

Galle, B., L. Klemedtsson, and D. W. T. Griffith, Application of an FTIR system for measurements of nitrous oxide fluxes using micrometeorological methods, an ultralarge chamber system, and conventional field chambers, J. Geophys. Res., this issue.

Hargreaves, K. J., U. Skiba, D. Fowler, J. Arah, F. G. Wienhold, 
L. Klemedtsson, and B. Galle, Measurement of nitrous oxide emission from fertilized grassland using micrometeorological techniques, J. Geophys. Res., this issue.

Houghton, J. T., B. A. Callander, and S. K. Varney (Eds.), Climate Change 1992: The Supplementary Report to the IPCC Scientific Assessment, 200 pp., Cambridge University Press, New York, 1992.

International Atomic Energy Agency (IAEA), Manual on measurement of methane and nitrous oxide emissions from agriculture, IAEA-TECDOC-674, Vienna, 1992.

International Global Atmospheric Chemistry (IGAC) Project, Trace Gas Exchange: Midlatitude Terrestrial Ecosystems and Atmosphere, Cambridge, Mass., 1992.

Leclerc, N. Y., and G. W. Thurtell, Footprint prediction of scaler fluxes using a Markovian analysis, Boundary Layer Meteorol., 52, 247-258, 1990.

Loftfield, N. S., R. Brumme, and F. Beese, Automated monitoring of nitrous oxide and carbon dioxide flux from forest soils, Soil Sci. Soc. Am. J., 56, 1147-1150, 1992.

Melillo, J. M., K. A. Smith, J. Bogner, P. Groffman, G. Harris, L. Klemedtsson, A. R. Mosier, and W. H. Su, in Exchanges of $\mathrm{N}_{2} \mathrm{O}$, $\mathrm{CH}_{4}$ and $\mathrm{CO}$ Between Terrestrial Ecosystems and the Atmosphere in Midlatitudes, report of IGAC Activity 7.2 Planning Workshop, Boulder, Colo., Sept. 1991, IGAC, Cambridge, Mass., 1992.

Oliver, M. A., and R. Webster, How geostatistics can help you, Soil Use and Management, 7, 206-217, 1991.

Robertson, G. P., Fluxes of nitrous oxide and other nitrogen trace gases from intensively managed landscapes: A global perspective, in Agricultural Ecosystem Effects on Trace Gases and Global Climate Change, ASA Spec. Publ. 55, pp. 95-108, Am. Stand. Assoc., New York, 1993.

Ryden, J. C., $\mathrm{N}_{2} \mathrm{O}$ exchange between a grassland soil and the atmosphere, Nature, 292, 235-237, 1981.

Sexstone, A. J., T. B. Parkin, and J. M. Tiedje, Temporal response of soil denitrification rates to rainfall and irrigation, Soil Sci. Soc. Am. J., 49, 99-103, 1985.

Skiba, U., K. J. Hargreaves, K. A. Smith, and D. Fowler, Fluxes of nitric and nitrous oxide from agricultural soils in a cool temperate climate, Atmos. Environ., 26(A), 2477-2488, 1992.

Smith, K. A., Soil aeration, Soil Sci., 123, 284-291, 1977.

Smith, K. A., G. P. Robertson, and J. M. Melillo, Exchange of trace gases between the terrestrial biosphere and the atmosphere in the mid-latitudes, in Global Atmospheric-Biospheric Chemistry, edited by R. G. Prinn, Plenum, New York, in press, 1994.

Smith, K. A., A. Scott, B. Galle, and L. Klemedtsson, Use of a long-path infrared gas monitor for measurement of nitrous oxide flux from soil, J. Geophys. Res., this issue.

Wienhold, F. G., H. Frahm, and G. W. Harris, Measurements of $\mathrm{N}_{2} \mathrm{O}$ fluxes from fertilized grassland using a fast response tunable diode laser spectrometer, J. Geophys. Res., this issue.

P. Ambus and S. Christensen, Institute of Population Biology, Copenhagen University, Universitetsparken 15, DK-2100, Copenhagen, Denmark.

J. R. M. Arah and K. A. Smith, Scottish Agricultural College, Department of Soil Science, West Mains Road, Edinburgh EH9 3JG, Scotland.

H. Clayton, School of Agriculture, University of Edinburgh, West Mains Road, Edinburgh EH9 3JG, Scotland.

D. Fowler, K. J. Hargreaves, and U. Skiba, Institute of Terrestrial Ecology, Bush Estate, Penicuik, Midlothian, EH26 OPH, Scotland.

B. Galle and L. Klemedtsson, Swedish Environmental Research Institute, P. O. Box 47086, S-40258 Gothenburg, Sweden.

G. W. Harris and F. G. Wienhold, Air Chemistry Department, Max Planck Institute for Chemistry, P. O. Box 3060, 55020, Mainz, Germany.

(Received August 18, 1993; revised March 1, 1994; accepted March 1, 1994.) 